\title{
MANAJEMEN PENANGANAN MUATAN REEFER CONTAINER DI MV. SAN PEDRO BRIDGE
}

\author{
Agus Hadi P. a, Suwiyadi ${ }^{\mathrm{b}}$ dan Muhammad Reza Wardani ${ }^{\mathrm{c}}$ \\ a dan b Dosen Program Studi Nautika PIP Semarang \\ ${ }^{\mathrm{c}}$ Taruna (NIT 50134882 N) Program Studi Nautika PIP Semarang
}

\begin{abstract}
ABSTRAK
MV San Pedro Bridge adalah kapal kontainer yang dapat memuat reefer container antar pulau dan pelabuhan melalui laut. Muatan reefer container bersifat mudah rusak akibat suhu yang tidak sesuai. Penanganan khusus untuk menghindari kerusakan muatan adalah proses yang menjadi perbedaan reefer container dengan muatan peti kemas lainnya dan menjadikannya kontainer dengan biaya jasa pengiriman yang berharga mahal diantara muatan peti kemas lainnya.

Penelitian dilaksanakan di MV San Pedro Bridge dari tanggal 3 Februari 2016 sampai dengan tanggal 7 Desember 2016. Penelitian ini menggunakan metode deskriptif - kualitatif. Sumber data yang diolah berdasarkan data primer dengan pengamatan dan wawancara langsung, dan data sekunder diambil berdasarkan buku manual, artikel internet dan jurnal.

Dari hasil penelitian dapat disimpulkan, dalam persiapan penanganan muatan dan pelaksanaan manajemen penanganan muatan selama pelayaran dilaksanakan sesuai panduan Bernhard Schulte Shipmanagement (BSM) Container Ship Manual, prinsip-prinsip utama pemuatan, dan sesuai dengan empat fungsi manajemen: Planning, Organizing, Actuating dan Controlling.
\end{abstract}

Kata kunci: reefer containers, suhu, manajemen

\section{ABSTRACT}

MV San Pedro Bridge is a container vessel shipping reefer containers inter island and port through the sea. Reefer container's cargo is very sensitive, and easily damaged because of improper temperature. Special requirement in reefer cargo handling in order to avoid cargo damage, make it has the most expensive freight cargo among the ordinary cargo container.

This research had been done on the MV San Pedro Bridge from 3 February 2016 up to 7 December 2016. This research using descriptive - qualitative method. The data based on primary data by observing and interviewing MV San Pedro Bridge directly. And secondary data based on manual books, internet and journals. Based on the results, author concludes the preparation and application reefer container handling management should be according to Bernhard Schulte Shipmanagement (BSM) Container Ship Manual Book, the main principle of cargo loading, and four functions of management: Planning, Organizing, Actuating, and Controlling.

Keywords: reefer containers, temperature, management 
Agus Hadi P. ${ }^{\text {a }}$, Suwiyadi ${ }^{\mathrm{b}}$ dan Muhammad Reza Wardani ${ }^{\mathrm{c}}$

\section{PENDAHULUAN}

Refrigated Cargo Container atau bisa disebut juga reefer container adalah jenis kontainer khusus yang digunakan untuk mengantarkan muatan yang sensitif terhadap perubahan suhu. Reefer container dapat menjaga suhu muatan atau ruangan di dalam kontainer yang dapat diatur dengan rentang temperatur dari $-40^{\circ} \mathrm{C}$ sampai $+30^{\circ} \mathrm{C}$. Jenis kontainer ini memiliki komponen elektronik dan sistem pendingin yang sangat bergantung pada daya listrik dengan rata-rata konsumsi 3 sampai $4 \mathrm{kWh}$ (tergantung juga pada kondisi dan jenis muatan) yang dihasilkan oleh generator. Dari generator yang terdapat di dalam ruang mesin, daya listrik dialirkan dan dihubungkan sampai kepada reefer socket yang terdapat di atas dek dan di dalam palka selama kapal bersandar dan berlayar di laut lepas.

Meningkatnya permintaan jasa pengangkutan reefer container dari tahun ke tahun membuktikan transportasi laut menjadi sarana yang baik untuk mengantarkan muatan dingin dan beku dari suatu tempat ke tempat lain yang harus melewati perairan seperti lintas sungai, antar pulau dan antar negara. Muatan yang biasa dibawa adalah hasil sumber daya alam, aneka hasil peternakan, aneka pertanian, bahan olahan atau hasil produksi pabrik yang bersifat mudah rusak akibat suhu yang tidak sesuai. Dengan adanya reefer container, konsumen dari seluruh penjuru dunia dapat menikmati produk segar yang berasal dari bagian dunia lain. Penanganan khusus untuk menghindari kerusakan muatan adalah proses yang menjadi perbedaan reefer container dengan muatan peti kemas lainnya dan menjadikannya kontainer dengan biaya jasa pengiriman yang berharga mahal diantara muatan peti kemas lainnya.
Bernhard Schulte Shipmanagement adalah perusahaan pelayaran yang bergerak di bidang jasa pengangkutan muatan internasional. Perusahaan ini mempunyai banyak kapal yang aktif beroperasi dalam pelayaran dunia. Kapal tempat peneliti melaksanakan praktek laut bernama MV Mol Growth (yang kemudian berganti nama menjadi MV San Pedro Bridge), kapal ini adalah kapal jenis kontainer yang dapat memuat reefer container.

Komponen dari reefer container bergantung pada sumber listrik dari kapal dan dapat rusak, dimana harus diganti atau dicabut secepatnya untuk menghindari kebakaran atau kerusakan komponen lainnya.Menurut pengalaman peneliti selama praktek layar, faktor-faktor yang dialami reefer container ketika dimuat di kapal antara lain posisi kontainer atau suhu yang berbeda dari data yang tertera di cargo manifest dengan keadaan sesungguhnya, reefer container yang mati karena kendala supply listrik, suku cadang yang habis atau tidak tersedia di kapal, dan beberapa kendala lain yang mengakibatkan muatan di dalam reefer container rusak atau membusuk.

Reefer container adalah salah satu kunci utama pendapatan dari beberapa perusahaan pelayaran. Namun jika terjadi kesalahan penanganan dalam pemuatan reefer container yang menyebabkan muatan rusak, hal ini dapat membuat perusahaan pelayaran rugi karena pelanggan dapat mengajukan cargo claim sebagai jaminan dan ganti rugi atas muatan yang rusak tersebut. Oleh karena itu, pelaksanaan manajemen penanganan muatan yang baik diperlukan untuk memastikan muatan reefer container dapat dimuat dan diantarkan dari pelabuhan asal ke pelabuhan tujuan.

Berdasarkan latar belakang yang telah diuraikan diatas, maka tujuan dari penelitian ini adalah untuk mengetahui dan 
mengkaji tentang manajemen penanganan reefer container di perusahaan Bernhard Schulte Shipmanagement di kapal MV San Pedro Bridge untuk meminimalisir bahkan menghilangkan kemungkinan kerusakan muatan yang menyebabkan cargo claim dari pihak charter kepada perusahaan untuk mengganti rugi atas rusaknya muatan tersebut. Sehingga peneliti dalam penelitian ini mengambil judul: "Manajemen Penanganan Muatan Reefer Container di MV San Pedro Bridge"

Berdasarkan latar belakang yang telah diuraikan di atas, maka rumusan masalah yang dibahas antara lain:

1. Persiapan-persiapan apa yang harus dilakukan dalam manajemen penanganan muatan reefer container di MV San Pedro Bridge?

2. Bagaimana pelaksanaan manajemen penanganan muatan reefer container di MV San Pedro Bridge selama pelayaran?

Kajian pustaka yang digunakan dalam penelitian ini antara lain:

1. Manajemen

Menurut Mulyono (2008:15) manajemen adalah proses pencapaian tujuan melalui kegiatan-kegiatan dan kerja sama orang lain. Manajemen berasal dari kata "manus" yang berarti tangan yang secara harfiah berarti menangani atau melatih kuda. Secara maknawiah berarti memimpin, membimbing atau mengatur. Beberapa fungsi manajemen yang membentuk suatu proses manajemen antara lain adalah:

\section{a. Planning (Perencanaan)}

Proses pemastian sasaran adalah suatu kegiatan menetapkan tujuan organisasi dan memilih cara terbaik untuk mencapai tujuan.

b. Organizing (Pengorganisasian)

Organizing adalah mengkoordinasi sumber daya, tugas dan otoritas diantara anggota organisasi agar tujuan organisasi dapat dicapai dengan efisien dan efektif.

c. Actuating (Penggerak, Pengaruhan, Pelaksanaan)

Kegiatan manajemen yang berupa tindakan untuk mengusahakan agar anggota kelompok dalam organisasi terdorong berkeinginan dan berusaha untuk mencapai sasaran sehingga sesuai dengan perencanaan manajemen.

d. Controlling (Pengendalian)

Adalah suatu aktifitas untuk menjamin perencanaan dilaksanakan berdasakan dengan standard. Berikut ini adalah fungsi dari controlling:

1) Mengumpulkan informasi yang mengukur kinerja terakhir dalam organisasi.

2) Membandingkan kinerja sekarang dengan standar kinerja yang telah ditentukan.

3) Menentukan perlunya memodifikasi kegiatan agar mencapai standar yang telah ditentukan.

4) Menentukan standar prestasi yang telah dicapai.

2. Penanganan Muatan

Menurut Arso Martopo dan Soegiyanto (2004:07) pengaturan dan teknik pemuatan di atas kapal merupakan salah satu kecakapan pelaut yang menyangkut berbagai macam aspek tentang bagaimana cara melakukan pemuatan di atas kapal, bagaimana cara melakukan perawatan muatan selama pelayaran, dan bagaimana cara melakukan pembongkaran di pelabuhan tujuan.

Stowage atau penanganan muatan yaitu suatu pengetahuan tentang memuat dan membongkar muatan dari dan ke atas kapal sedemikian rupa agar terwujud 5 prinsip pemuatan yang baik. Lima prinsip pemuatan yang harus 
Agus Hadi P. ${ }^{\text {a }}$, Suwiyadi ${ }^{\mathrm{b}}$ dan Muhammad Reza Wardani ${ }^{\mathrm{c}}$

benar-benar diperhatikan dan dilaksanakan. Prinsip-prinsip utama pemuatan:

a. Melindungi awak kapal dan buruh;

b. Melindungi kapal;

c. Melindungi muatan;

d. Melakukan muat bongkar secara cepat dan sistematis;

e. Mencegah terjadinya ruang rugi.

\section{Reefer container}

Berdasarkan judul peneliti yang erat kaitannya dengan reefer container, menurut Istopo (2000:365) reefer container adalah kontainer yang dilengkapi dengan lapisan dalam, mesin pendingin atau pemanas guna memuat barang-barang yang harus dijaga kesegarannya sampai tangan konsumen. Sedangkan menurut Tim PIP Semarang dalam buku Penanganan dan Pengaturan Muatan (2004:20) reefer container adalah peti kemas standar biasa (closed container) yang dilengkapi dengan alat pendingin yang dihubungkan dengan generator tersendiri (demountable generator).

Kontainer sebagai tempat muatan dingin dan beku mutlak digunakan dalam pengangkutan di kapal. Pada awal perkembangannya, ukuran reefer container belum distandarisasi, kemudian mulai ada standarisasi ukuran kontainer dengan ukuran 20 feet, 40 feet, 45 feet dan menggunakan ukuran High Cube (HC) atau peti kemas tinggi untuk membawa berbagai jenis muatan dingin dan beku.

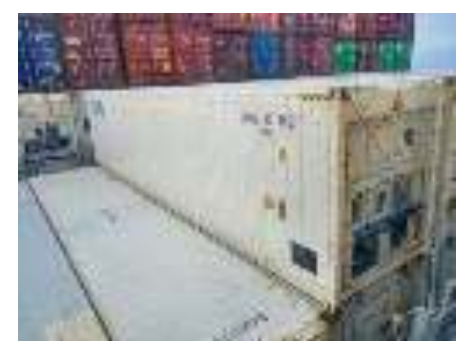

Gambar 1. Reefer container 40 feet
4. Jenis atau golongan Reefer Cargo Reefer cargo dibagi menjadi dua golongan yaitu:

a. Muatan dingin

Menurut Istopo (2000:310) muatan dingin adalah muatan yang bersuhu pada kisaran rentang $0.5^{\circ} \mathrm{C}$ $\left(0.9^{\circ} \mathrm{F}\right)$. Muatan ini harus didinginkan untuk mempertahankan kesegaran muatan untuk menghambat kegiatan mikro organisme serta proses kimia. Menurut Soegiyanto \& Martopo (2004:3) muatan dingin adalah muatan yang memerlukan ruangan khusus yang dilengkapi dengan alat pendingin. Contoh muatan dingin yang dimuat di MV San Pedro Bridge adalah: buah dan sayur segar; daging dan ikan segar; produk susu dan telur; jus segar; tanaman hidup dan bunga; serta peralatan elektronik dan kimia.

b. Muatan beku

Menurut Istopo (2000:311) muatan beku adalah muatan yang dimuat dalam keadaan beku keras bersuhu sekitar $-20^{\circ} \mathrm{C}\left(-4^{\circ} \mathrm{F}\right)$ atau lebih rendah. Muatan dalam keadaan beku berfungsi untuk menghindari atau menghentikan aktivitas dan kemungkinan pertumbuhan bakteri dan mikro organisme. Fungsi dari pembekuan itu sendiri adalah untuk mencegah terjadinya pembusukan muatan oleh bakteri. Contoh muatan beku yang dimuat di MV San Pedro Bridge adalah: daging dan ikan beku; makanan siap saji beku; serta roti dan olahan pertanian lain.

\section{Bay plan container (Stowage plan)}

Menurut Soegiyanto dan Arso Martopo (2004:6) bay plan adalah suatu bagan penempatan kontainer di atas kapal baik di dalam palka maupun di 
atas dek atau stowage plan untuk kapal kontainer. Menurut (Tim BPLP Semarang: 163) container bay plan adalah bagan pemuatan peti kemas secara membujur, melintang dan tegak. Membujur ditandai dengan nomor bay mulai dari depan ke belakang, dengan catatan nomor ganjil untuk peti kemas ukuran 20 feet dan nomor genap untuk peti kemas ukuran 40 feet. Tegak/tier dihitung dari bawah ke atas, di dalam palka dimulai dengan nomor 02, 04, 06 dan seterusnya, sedangkan di atas geladak dimulai dengan nomor 82,84 , 86 dan seterusnya. Arah melintang disebut dengan nomor row dimulai dari tengah dan dilihat dari belakang. Dari tengah ke kanan row 01, 03, 05, 07, 09, dan seterusnya sedangkan dari tengah ke kiri row 02, 04, 06, 08, dan seterusnya.

Bay plan biasanya berbentuk lembaran-lembaran kertas yang diberikan pihak darat ke pihak kapal, dalam hal ini chief officer sebagai perwira yang mengurus penanganan muatan di atas kapal. Dalam bay plan dapat dilihat data-data mengenai kontainer yang akan dimuat, yaitu: nomor kontainer, posisi kontainer diletakkan berdasarkan (bay, row dan row), tujuan bongkar, berat kontainer dan isi dari kontainer khusus untuk refrigated cargo. Agar tidak terjadi kesalahan dalam pemuatan dan pengawasan maka setiap kontainer dengan tujuan berbeda diberi inisial kota tujuan atau dapat juga dengan pemberian warna yang berbeda.
Di bawah ini adalah kerangka pikir dalam penelitian.

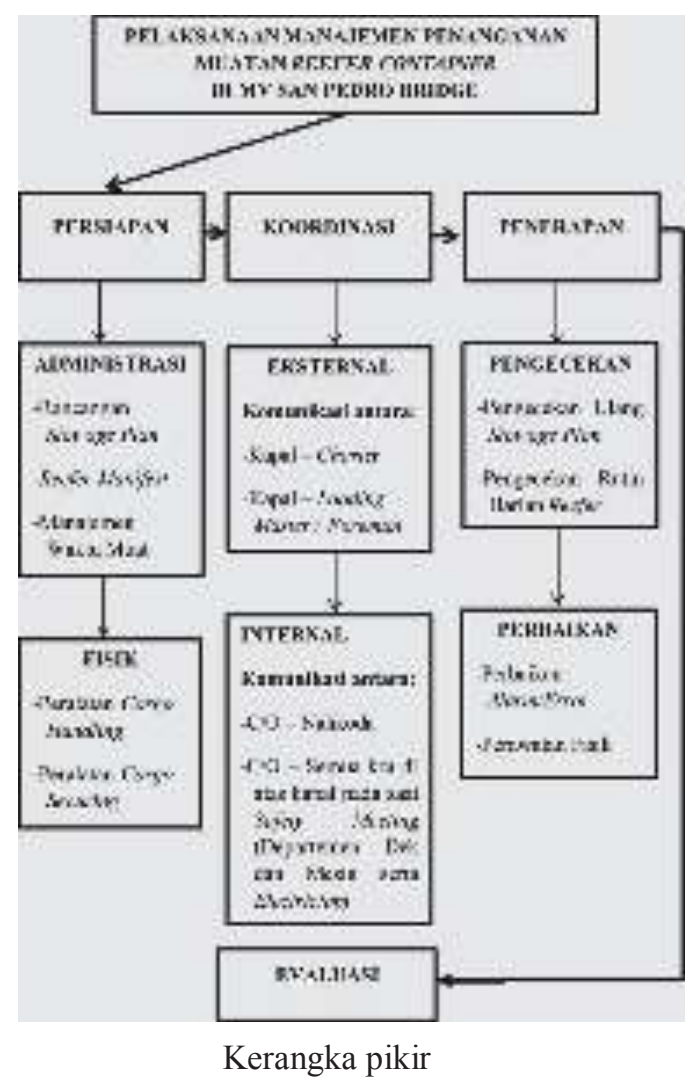

\section{METODOLOGI}

Metode penelitian yang digunakan oleh peneliti adalah metodologi penelitian deskriptif kualitatif untuk menggambarkan dan menguraikan objek yang diteliti serta kaidah-kaidah yang diambil dari teori-teori yang berhubungan dengan topik yang dibahas, selain itu juga menggunakan pendekatan di lapangan yang telah dilaksanakan selama praktek laut.

1. Metode deskriptif

Metode penelitian deskriptif adalah metode penelitian yang dilakukan untuk mengetahui nilai variabel mandiri atau lebih (independen) tanpa membuat perbandingan atau menggabungkan antara variabel satu dengan yang lain (Sugiyono, 2012:35). Pada bagian ini peneliti akan mendeskripsikan tentang persiapan sebelum memuat reefer container dan pelaksanaan penanganan 
Agus Hadi P. ${ }^{\text {a }}$, Suwiyadi ${ }^{\mathrm{b}}$ dan Muhammad Reza Wardani ${ }^{\mathrm{c}}$

muatan selama pelayaran di MV San Pedro Bridge.

2. Metode kualitatif

Menurut Sugiyono (2012:13), metode penelitian kualitatif adalah metode penelitian yang berlandaskan pada filsafat postpositivisme, digunakan untuk meneliti pada kondisi objek yang alamiah, (sebagai lawannya adalah eksperimen) di mana peneliti adalah sebagai instrumen kunci, teknik pengumpulan data dilakukan secara triangulasi (gabungan), analisis data bersifat induktif/kualitatif, dan hasil penelitian lebih menekankan makna generalisasi.

Dalam pembahasan peneliti memaparkan hasil dari semua studi dan penelitian mengenai suatu objek yang diperoleh, baik hal-hal yang bersifat teori juga memuat hal-hal yang bersifat praktis, dalam artian bahwa selain ditulis dari beberapa literatur buku, juga bersumber dari objek-objek penelitian yang juga terdapat dalam buku kemaritiman. Penggunaan aspek observasi atau pengamatan sangat berperan dalam penelitian ini. Hasil observasi atau pengamatan pelaksanaan di atas kapal yang dilakukan oleh peneliti mengenai pelaksanaan manajemen penanganan muatan reefer container akan digabungkan dengan sumber data yang lain seperti, hasil wawancara dan dokumentasi di atas kapal selama melakukan penelitian sehingga mencapai hasil yang maksimal.

Penelitian dilaksanakan dari tanggal 3 Februari 2016 sampai dengan tanggal 7 Desember 2016 di kapal MV San Pedro Bridge dari perusahaan K-LINE. Kapal ini memiliki bendera kebangsaan Hong Kong dan dimiliki oleh Bernhard Schulte Shipmanagement (Hong Kong) Ltd. yang beralamat di BSM Hong Kong, 2608, K. Wah Centre, 191 Java Road, North Point, Hong Kong.
Sumber data pada penelitian ini menggunakan dua jenis data, yaitu:

1. Data primer

Menurut Bungin (2004:122), data primer adalah data yang diperoleh langsung dari sumber aslinya yaitu instansi atau perusahaan yang menjadi objek penelitian yang berupa kata-kata atau tindakan dari informan. Sumber. Data yang paling utama didapat dari kata-kata, tindakan, selebihnya data tambahan. Data yang diambil merupakan data yang diperoleh dari observasi langsung dan wawancara kepada perwira di kapal MV San Pedro Bridge.

2. Data sekunder

Menurut Sugiyono (2008:225), data sekunder adalah sumber data yang tidak langsung memberikan data kepada pengumpul data, yang lebih terdahulu dikumpulkan dan dilaporkan oleh orang yang tidak sedang meneliti walaupun data yang diperoleh merupakan data asli data ini diperoleh dari literatur, buku-buku yang berkaitan dengan objek yang sedang diteliti. Data sekunder adalah data primer yang diolah atau disajikan oleh pihak lain yang diperoleh secara tidak langsung dari objek penelitian.

Dalam penelitian ini peneliti mendapatkan data sekunder dari dokumen-dokumen resmi perusahaan, buku pedoman kapal kontainer perusahaan (BSM Container Ship Manual), website di internet, jurnaljurnal pendukung yang ada kaitan dalam penelitian, dan studi kepustakaan lain yang relevan dengan penelitian ini.

\section{HASIL PENELITIAN DAN PEMBAHASAN}

\section{Persiapan-persiapan yang harus dilakukan dalam manajemen}


penanganan muatan reefer container di MV San Pedro Bridge

Persiapan yang dilaksanakan sebelum penanganan muatan reefer container berdasarkan buku panduan Bernhard Schulte Shipmanagement, Container Ship Manual (2016:10) dan observasi peneliti dan observasi langsung peneliti.

a. Pembersihan ruangan muat kapal

Pembersihan di palka membutuhkan prosedur yang ketat, karena di dalam palka kapal kontainer dapat digolongkan ke dalam ruangan tertutup atau dalam istilah pelayaran disebut dengan enclosed space. Palka dapat digolongkan menjadi enclosed space dikarenakan tidak mendapat sirkulasi udara yang mencukupi.

Sebelum melakukan pembersihan, perlu dipastikan ruangan telah mendapat ventilasi yang mencukupi dan Mualim I diwajibkan mengisi enclosed space entry permit form, atau formulir perizinan untuk memasuki ruangan tertutup dan melakukan aktivitas disana. Setelah semua prosedur di dalam formulir perizinan untuk memasuki ruangan tertutup telah dilaksanakan, kegiatan pembersihan ruangan palka dapat dimulai.

Pembersihan dimulai dari menyapu debu, kotoran dan sisa hasil perawatan dek yang dikumpulkan. Jika diperlukan, palka dapat dibersihkan dengan air tawar dan air diberi cairan kimia untuk menghilangkan bau. Setelah itu ventilasi palka dibuka untuk mempercepat proses pengeringan.

b. Pembuatan Bay Plan atau Stowage Plan

1) Pengertian dari Bay Plan atau Stowage Plan

Menurut Soegiyanto dan Arso Martopo (2004:6) bay plan adalah suatu bagan penempatan container di atas kapal baik di dalam palka maupun di atas dek atau stowage plan untuk kapal kontainer. Menurut (Tim BPLP Semarang: 163) container bay plan adalah bagan pemuatan peti kemas secara membujur, melintang dan tegak. Bay plan atau stowage plan biasanya berbentuk lembaran-lembaran kertas yang diberikan pihak darat ke pihak kapal, dalam hal ini chief officer sebagai perwira yang mengurus penanganan muatan di atas kapal. Dalam bay plan dapat dilihat data-data mengenai kontainer yang akan dimuat, yaitu: nomor kontainer, posisi kontainer diletakkan berdasarkan (bay, row dan tier), tujuan bongkar, berat kontainer dan isi dari kontainer khusus untuk refrigated cargo. Agar tidak terjadi kesalahan dalam pemuatan dan pengawasan maka setiap kontainer dengan tujuan berbeda diberi inisial kota tujuan atau dapat juga dengan pemberian warna yang berbeda. Kebijakan ini dapat berbeda menyesuaikan kapal dan perusahaan masingmasing.

2) Jenis-jenis Stowage Plan

Stowage plan memiliki dua macam yang berbeda, yaitu:

a) Tentative Stowage Plan

Tentative Stowage Plan adalah rencana pemuatan kontainer yang berupa gambaran ancarancar untuk suatu rencana pengaturan muatan yang dibuat sebelum kapal tiba di pelabuhan muat atau sebelum pelaksanaan pemuatan. Tentative Stowage Plan dibuat berdasarkan Booking List atau 
Agus Hadi P. ${ }^{\text {a }}$, Suwiyadi ${ }^{\mathrm{b}}$ dan Muhammad Reza Wardani ${ }^{\mathrm{c}}$

Shipping Order yang diterima untuk suatu pelabuhan tertentu.

b) Final Stowage Plan

Final Stowage Plan adalah gambaran informasi yang menunjukkan keadaan sebenarnya dari letak-letak muatan beserta jumlah dan beratnya pada tiap-tiap palka yang dilengkapi dengan Consignment mark untuk masing-masing pelabuhan tertentu. Setelah selesai mengadakan kegiatan pengaturan muatan, maka kondisi muatan yang sebenarnya yang terdapat didalam ruang muat/palka dapat dilihat dalam Stowage Plan ini, oleh kerena itu, maka Stowage Plan seyogyanya dibuat seteliti mungkin sebab termasuk salah satu dokumen yang cukup penting dan dapat berfungsi sebagai bahan/bukti pertanggung jawaban atas pengaturan muatan di dalam ruang muat/palka bila terjadi tuntutan ganti rugi (cargo claim) dari pemilik muatan (Consignee).

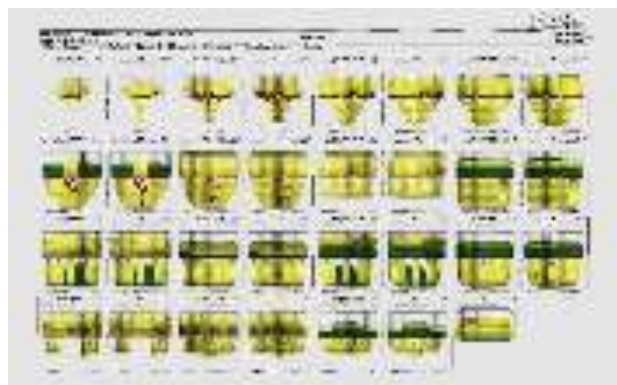

Gambar 2. Final stowage plan, dengan sistem tiga warna. Normal container (kuning), reefer container (hijau), dan dangerous goods container (merah)

c. Persiapan dokumen muatan

1) Cargo Manifest

Pengertian dari cargo manifest adalah dokumen yang berisi informasi detail mengenai seluruh kargo yang dibawa, meliputi informasi pengirim, informasi barang yang dibawa, informasi penerima barang, dan lain sebagainya. Dokumen ini digunakan pada semua jenis pengangkutan baik darat, laut, maupun udara untuk mencatat seluruh bawaan.

2) Reefer Manifest

Reefer manifest adalah daftar muatan reefer container yang diberikan oleh shipper kepada pihak kapal. Reefer manifest menjadi acuan pihak kapal untuk melakukan tindakan penanganan menyesuaikan informasi yang tertera didalamnya. Sesaat setelah kedatangan kapal di pelabuhan muat, Chief officer harus mendapat daftar muatan kontainer dan reefer manifest, yang didalamnya terdapat informasi mengenai:

1) Pelabuhan muat dan pelabuhan bongkar;

2) Isi dari muatan reefer;

3) Suhu yang diinginkan (set point);

4) Informasi pengaturan ventilasi;

5) Tanggal pengisian muatan reefer container;

6) Instruksi pengangkutan.

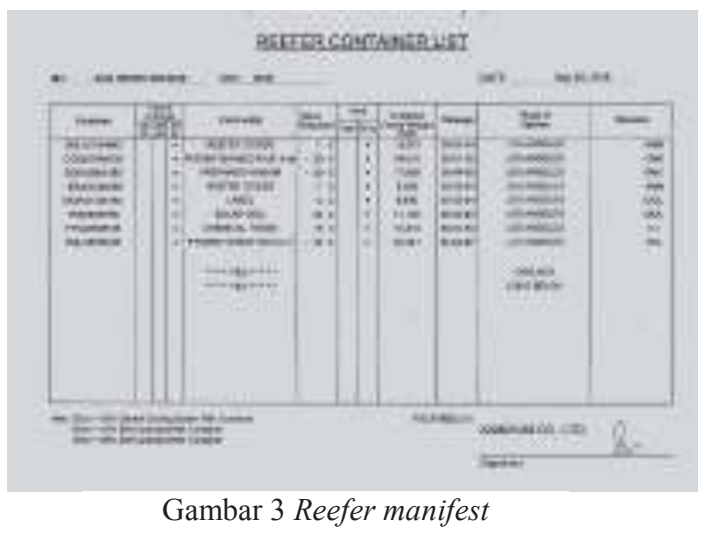


d. Persiapan awak kapal sebelum proses pemuatan dimulai

1) Nakhoda

Nakhoda sebagai penanggung jawab utama yang bertanggung jawab keseluruhan untuk memastikan awak kapal siap untuk melakukan proses bongkar muat. Nakhoda juga bertanggung jawab untuk menginformasikan segala kendala yang tidak memuaskan atau kondisi yang tidak aman terhadap reefer container dan meminta solusi dari segala kendala yang dialami dari pihak Charter dan Marine Superintendent.

2) Chief Officer (Mualim I)

Chief Officer atau Mualim I selaku Cargo Officer atau perwira yang bertanggung jawab untuk penanganan muatan, harus mengkaji ulang cargo manifest dan reefer manifest menyesuaikan dengan keadaan kapal yang sesungguhnya. Jika terdapat halhal yang perlu dikoordinasikan ulang, chief officer dan shipper masih mempunyai waktu untuk mengantisipasinya.

3) Officer on Watch (Mualim Jaga)

Officer on Watch atau Mualim Jaga adalah perwira yang ditugaskan Chief Officer untuk memantau jalannya bongkar muat di pelabuhan. Di MV San Pedro Bridge yang menjadi Mualim Jaga adalah Second Officer (2/O) dan Third Officer (3/O).

Mualim jaga mempunyai fungsi dan tugas untuk memastikan semua kontainer, termasuk reefer container, berada pada posisi yang tepat. Dan ketika reefer container sudah diletakkan, kabel reefer plug segera ditancapkan lalu dicatat suhu permulaannya dan diteliti ventilasinya apakah sudah sesuai dengan reefer manifest. Segala hal yang janggal atau tidak sesuai bisa langsung dilaporkan kepada Chief Officer dan Electrician.

4) Chief engineer (Kepala Kamar Mesin)

Berdasarkan Bernhard Schulte Shipmanagement (BSM), Appendix to Container Ship Manual Document No. 12873 (2016:8), chief engineer bertanggung jawab untuk memastikan dan menyediakan daya listrik yang mencukupi untuk memuat reefer container di atas kapal. Selain itu, chief engineer juga nantinya bertanggung jawab untuk perawatan dan perbaikan reefer container. Chief engineer dapat mendelegasikan tanggung jawab ini kepada engineer lain (di kapal MV San Pedro Bridge chief engineer mendelegasikan tugas kepada electrician), tapi tentu masih dalam pengawasan dan pertanggungjawaban chief engineer.

5) Electrician

Electrician adalah orang yang bertanggung jawab untuk kelistrikan kapal dan penanganan reefer container, penanganan muatan dalam peti kemas yang termasuk ke dalam muatan beku atau muatan reefer container berbeda dengan muatan peti kemas lainnya. Perbedaan yang paling signifikan adalah reefer container membutuhkan sumber listrik atau power supply yang dihasilkan dari generator, sedangkan peti kemas biasa tidak membutuhkan sumber listrik.

6) Bosun dan awak kapal

Bosun bertanggung jawab atas seluruh kinerja awak kapal dek. 
Agus Hadi P. ${ }^{\text {a }}$, Suwiyadi ${ }^{\mathrm{b}}$ dan Muhammad Reza Wardani ${ }^{\mathrm{c}}$

Persiapan sebelum melakukan pemuatan antara lain persiapan peralatan yang terdiri dari pemeriksaan peralatan cargo handling dan cargo securing harus dipastikan layak dan siap pakai seperti lashing bar, twist lock, twist tacker, spanner serta memastikan peralatan untuk menyambungkan listrik kapal ke reefer container seperti kabel, reefer plug, koneksi listrik dapat digunakan.

e. Persiapan peralatan perlindungan kapal (lashing equipment)

Sistem pelasingan di MV San Pedro Bridge menggunakan sistem pelasingan yang tertera pada Container Loading Plan yang diterbitkan oleh galangan kapal Hyundai Samho Heavy Industries Co., LTD. Berdasarkan pada Bernhard Schulte Shipmanagement (BSM) Container Ship Manual (2016:16). Adapun peralatan lashing yang digunakan di kapal MV San Pedro Bridge antara lain:

1) Twistlock, alat ini digunakan untuk mengikat dan mengunci peti kemas dengan peti kemas lain secara bertumpuk ke atas. Adapun jenis-jenisnya antara lain manual twistlock, semi automatic twistlock, dan full automatic twistlock.

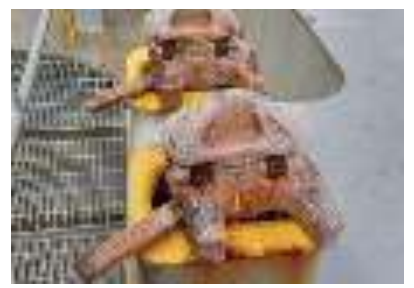

Gambar 4. Manual twistlock

2) Turn Buckle, alat ini biasanya dipasang di geladak di tempattempat lashing deck. Berbentuk berupa dua buah batang berulir di mana salah satu ujungnya mempunyai ikatan berupa segel dan ujung lainnya berbentuk kaitan ganco yang nantinya dihubungkan kemata dari lasing rod. Bila bagian tengahnya diputar maka kedua batang berulir akan berputar mengencang ataupun mengendor.

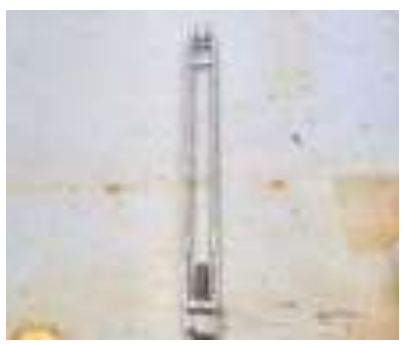

Gambar 5. Turn buckle

3) Lashing Bar, alat ini berupa stock atau batang besi dengan diameter kira-kira $3.0 \mathrm{~cm}$ di mana panjangnya ada bermacammacam, tergantung pada tingkat atau susunan keberapa dari peti kemas yang akan dilasing.

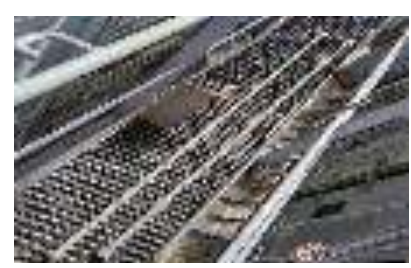

Gambar 6. Lashing bar

4) Extension Rod, alat ini berupa sebuah batang berukuran $40.0 \mathrm{~cm}$ yang dapat dipasang pada ujung lashing bar dan ujung lainnya dipasang pada turn buckle. Tujuan batang ini adalah untuk menambah panjang dari lashing bar untuk memudahkan menjangkau bagian kontainer yang jauh. 


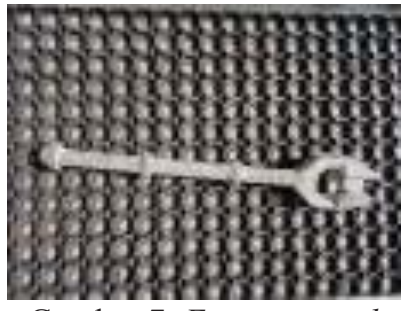

Gambar 7. Extension rod

\section{Pelaksanaan manajemen penanganan muatan reefer container di MV San Pedro Bridge selama pelayaran.}

Pelaksanaan manajemen penanganan reefer container harus sesuai dengan proses manajemen antara lain: Planning (perencanaan), Organizing (pengorganisasian), Actuating (pelaksanaan), dan Controlling (pengendalian). Begitu pula dalam pelaksanaan penanganan muatan yang dilakukan harus sesuai dengan prinsipprinsip utama pemuatan, yaitu: melindungi awak kapal, melindungi kapal, melindungi muatan, melakukan bongkar muat secara cepat dan sistematis, dan mencegah terjadinya ganti rugi.

a. Perencanaan penempatan reefer container ketika proses pemuatan

Penanganan dan pemuatan reefer container ketika proses pemuatan harus sesuai dengan rencana pemuatan atau cargo stowage plan dan reefer manifest yang telah disepakati oleh pihak kapal dan shipper. Hal ini untuk memudahkan pengawasan ketika dalam pelayaran dan dapat memudahkan dua pihak untuk memastikan semua container telah dimuat dengan sesuai. Dan yang perlu diperhatikan dan dilaksanakan adalah prinsip-prinsip utama pemuatan.

Sesaat setelah reefer container dimuat di atas kapal, kabel reefer harus segera ditancapkan pada reefer plug yang berada pada setiap cross deck antara dua bay agar sistem pendingin di dalam kontainer berfungsi. Suhu awal, keterangan ventilasi, dan jika ada informasi tambahan segera dicatat pada $\log$ book, laporan awal ini harus dikirim kepada perusahaan tidak lebih dari 1 x 24 jam setelah kapal berangkat dari pelabuhan.

b. Koordinasi dan kerjasama antara awak kapal dengan pihak pelabuhan

Koordinasi dan komunikasi antar awak kapal dilakukan ketika toolbox meeting. Mualim I, perwira jaga, dan seluruh awak kapal melakukan pertemuan membahas tentang bagaimana proses bongkar-muat akan berlangsung. Pembagian tugas dan tanggung jawab seluruh awak kapal dapat diketahui ketika pertemuan toolbox meeting ini. Mualim I akan membuat chief mate standing order yang bisa dilihat oleh seluruh awak kapal di cargo office room.

Komunikasi pihak kapal dengan pihak pelabuhan harus saling menghargai dan terjalin baik demi lancarnya proses pemuatan. Contohnya ketika laut mulai pasang, kapal akan semakin naik dan tali tross akan menjadi kendor. Tali tross yang kendor mengakibatkan posisi kapal tidak sepenuhnya sandar pararel dengan jetty pelabuhan. Hal ini akan menyusahkan crane untuk meletakkan kontainer di atas kapal dan berakibat pada besarnya kemungkinan kerusakan pada komponen bagian kapal jika crane memaksakan muatan untuk dimuat.

c. Pembuatan final stowage plan

Setelah semua kontainer telah dimuat di atas kapal, chief officer bertanggung jawab untuk membuat final stowage plan, berisi informasi yang hampir sama dengan tentative stowage plan namun bedanya adalah di dokumen ini harus disampaikan informasi yang benar-benar nyata. 
Agus Hadi P. ${ }^{\text {a }}$, Suwiyadi ${ }^{\mathrm{b}}$ dan Muhammad Reza Wardani ${ }^{\mathrm{c}}$

Berisi semua informasi terbaru mengenai informasi yang menunjukkan keadaan sebenarnya dari letak-letak muatan beserta jumlah dan beratnya pada tiap-tiap palka yang dilengkapi dengan Consignment mark untuk masingmasing pelabuhan tertentu.

d. Tindakan pengawasan terhadap reefer container selama pelayaran

Ada berbagai faktor yang menyebabkan suhu reefer container dapat berubah dan kendala yang terjadi dengan reefer container berkaitan dengan suku cadang maupun kelistrikan kapal sehingga dapat berpengaruh pada kualitas muatan di dalam reefer container. Oleh sebab itu, pengecekan rutin harian sangat penting dilakukan untuk tetap mengetahui status reefer container masih dalam kondisi normal atau terdapat kendala yang harus segera diselesaikan.

Pengecekan dilaksanakan minimal dua kali dalam satu hari, jika terjadi kendala diperlukan pemantauan intensif. Segala malfungsi reefer container yang terjadi wajib dilaporkan kepada charter melalui e-mail segera.

e. Perbaikan kendala dalam penanganan reefer container selama pelayaran

Kendala-kendala yang sering muncul dalam penanganan reefer container antara lain, perbedaan suhu yang besar antara suhu set point dengan suhu sebenarnya, ketidaksesuaian data suhu set point yang tertera pada cargo manifest dengan suhu set point yang tertera di layar sensor reefer, minimalnya suku cadang yang tersedia atau suku cadang yang telah dipesan tidak kunjung datang, kendala cuaca buruk ketika melaksanakan pengecekan rutin dan kendala waktu untuk menyelesaikan masalah jika alarm baru diketahui sore hari.

Disini adalah tugas dari Electrician untuk menangani reefer container yang memiliki kendala. Ketika menemukan kendala dalam pengecekan rutin harian, electrician menulis malfunction report atau berita acara yang berisi kendala atau alarm apa yang muncul, posisi container, serta informasi umum mengenai reefer container tersebut. Berita acara ini dikirim ke perusahaan dan charter, lalu dilakukan penanganan awal sesuai arahan dari manual book pabrikan. Perusaaan akan mengirimkan balasan mengenai perijinan untuk melakukan penanganan dan arahan lebih lanjut. Jika crew kapal tidak bisa menangani malfungsi dan reefer container tidak dapat diperbaiki, pihak kapal dapat meminta untuk membongkar muatan di pelabuhan selanjutnya.

\section{PENUTUP}

Berdasarkan uraian-uraian pada bab sebelumnya tentang "Manajemen Penanganan Muatan Reefer Container di MV. San Pedro Bridge", maka sebagai bagian akhir dari penelitian ini peneliti memberikan kesimpulan dan saran yang berkaitan dengan masalah yang dibahas, yaitu:

\section{A. Simpulan}

Berdasarkan uraian-uraian pada bab sebelumnya, maka peneliti mengambil beberapa kesimpulan sebagai berikut:

a. Persiapan-persiapan yang harus dilakukan dalam manajemen penanganan muatan reefer container di MV. San Pedro Bridge adalah persiapan yang dimulai dari persiapan ruang muat, persiapan 
dokumen (meliputi rancangan stowage plan dan reefer manifest), toolbox meeting bersama awak kapal, persiapan peralatan cargo handling dan cargo securing serta memastikan peralatan untuk menyambungkan listrik kapal ke reefer container semuanya layak dan siap pakai.

b. Pelaksanaan manajemen penanganan muatan reefer container di MV. San Pedro Bridge selama pelayaran antara lain memastikan penempatan muatan yang sesuai; koordinasi dengan sesama awak kapal melalui tool box meeting serta dengan pihak pelabuhan dan perusahaan; pembuatan final stowage plan; pengawasan rutin setiap hari untuk memeriksa reefer container; dan perbaikan kendala reefer container selama dalam pelayaran.

\section{B. Saran}

Dari kesimpulan di atas maka peneliti dapat memberikan saran mengenai permasalahan yang dibahas sebelumnya untuk dijadikan pedoman dalam menyelesaikan masalah yang terjadi antara lain:

a. Sebaiknya persiapan penanganan muatan peti kemas refrigated cargo container atau reefer yang berisi muatan beku atau muatan dingin sebelum dimuat di atas kapal dilaksanakan dengan prosedur yang telah ditentukan dan disesuaikan dengan panduan dalam Bernhard Schulte Shipmanagement (BSM) Container Ship Manual agar reefer container bisa dimuat di atas kapal dengan aman.

b. Disarankan kepada seluruh awak kapal untuk lebih meningkatkan perhatian dalam hal melaksanakan penanganan selama pelayaran sesuai dengan proses manajemen antara lain: Planning (perencanaan),
Organizing (pengorganisasian), Actuating (pelaksanaan), dan Controlling (pengendalian). Serta sesuai dengan prinsip-prinsip utama pemuatan, yaitu: melindungi awak kapal, melindungi kapal, melindungi muatan, melakukan bongkar muat secara cepat dan sistematis, dan mencegah terjadinya ganti rugi.

\section{DAFTAR PUSTAKA}

Bernhard Schulte Shipmanagement, BSM. 2016. Container Ship Manual. Bernhard Schulte Shipmanagement, BSM copyright

Bungin, M Burhan. 2004. Metodologi Penelitian Kuantitatif; Komunikasi, Eknomi dan Publik serta Ilmu-Ilmu Sosial lainnya. Jakarta: Kencana hlm. 122

Herdiansyah, Haris. 2013. Wawancara, Observasi, Dan Focus Groups. Jakarta: Rajawali Pers

Istopo. 2000. Kapal dan Muatannya. Jakarta: Koperasi Karyawan BP3IP

Ghony, M. Djunaidi dan Fauzan Almanshur. 2012. Metodologi Penelitian Kualitatif. Yogyakarta: Ar-Ruzz Media

Sugiyono. 2008. Metode Penelitian Kuantitatif, Kualitatif, dan $R \& D$. Bandung: Alfabeta

Mulyono. 2008. Manajemen Admisitrasi \& Organisasi Yogjakarta: Ar-ruzz Media

Martopo, Arso dan Soegiyanto. 2004. Penanganan dan Pengaturan Muatan. Semarang : Politeknik Ilmu Pelayaran Semarang 
Manajemen Penanganan Muatan Reefer Container Di Mv. San Pedro Bridge

Agus Hadi P. ${ }^{\mathrm{a}}$, Suwiyadi ${ }^{\mathrm{b}}$ dan Muhammad Reza Wardani ${ }^{\mathrm{c}}$

Sudjatmiko, F. D. C. 1995. Pokok-Pokok Pelayaran Niaga. Jakarta : Bhratara

Pengertian charter party:

http://www.maritimeworld.web.id/ 2013/11/Charter-Party-Dan-

Standar-Perjanjian-Penyewaan-
Kapal.html (akses tanggal 23/10/2017 jam 11.30)

Pengertian frozen cargo dan chilled cargo: https://www.apl.com/wps/portal/apl/aplhome/services/refrigeratedcargo/knowingyourcargo/ (akses tanggal 23/10/2017 jam 11.40) 